\title{
SETORES DE CUIDADO À SAÚDE E SUA INTER-RELAÇÃO NA ASSISTÊNCIA DOMICILIAR AO DOENTE CRÔNICO
}

\author{
Health care sectors and their interrelation in the context of nursing care of the chronic \\ patient
Sectores de cuidado a la salud y su interrelación en la asistencia domiciliar al enfermo crónico

Raquel Pötter Garcia ${ }^{1}$

Maria de Lourdes Denardin Budó

Stefanie Griebeler Oliveira ${ }^{3}$

Margrid Beuter ${ }^{4}$

Nara Marilene Oliveira Girardon-Perlini ${ }^{5}$

\section{RESUMO}

Objetivou-se descrever a inter-relação e comunicação nos setores de cuidado à saúde sob a perspectiva de cuidadores familiares de adoecidos crônicos com doença incapacitante. Estudo qualitativo, descritivo e exploratório, realizado com 11 cuidadores familiares de pacientes adscritos em uma Estratégia de Saúde da Família localizada no município de Santa Maria, Rio Grande do Sul. Os cuidadores familiares foram indicados pela equipe de saúde da unidade. A coleta de dados ocorreu de julho a setembro de 2010 e desenvolveu-se com entrevistas narrativas, orientadas por eixos norteadores. Da análise de conteúdo temática surgiram categorias relacionadas à comunicação e às relações interpessoais entre profissionais, cuidadores familiares e doentes, além das interfaces entre os setores de cuidado à saúde. Há necessidade de uma comunicação efetiva entre os setores de cuidado, de maneira que atuem conjuntamente, permitindo troca de saberes que auxiliem no enfrentamento do processo de doença.

Palavras-chave: Enfermagem. Doença crônica. Assistência domiciliar. Cuidadores. Comunicação.

\begin{abstract}
The aim of this article is to describe the inter-relation and communication regarding sectors of health care, under the perspective of family caregivers of chronic patients with a disease which causes disability. It is a qualitative, descriptive and exploratory study, with 11 family caregivers registered in a Family Health Strategy in Santa Maria, Rio Grande do Sul. Family caregivers were indicated by the health care team. Data collection happened from July to September of 2010 and was developed through narrative interviews, oriented by guiding themes. Thematic content analysis was carried out and the categories which emerged from such analysis concerned communication and interpersonal relationships among professionals, family caregivers and patients, and the interface among the health care sectors. The need of effective communication among the health care sectors is highlighted, allowing them to act together, enabling an exchange of knowledge that may help throughout the process of facing the disease.
\end{abstract}

Keywords: Nursing. Chronic disease. Home nursing. Caregivers. Communication.

\section{Resumen}

Se objetiva describir la interrelación y comunicación en los sectores de cuidado a la salud, bajo la perspectiva de cuidadores familiares de enfermos crónicos con enfermedad discapacitante. Estudio cualitativo, descriptivo y exploratorio, realizado con 11 cuidadores familiares de pacientes adscritos en una Estrategia de Salud de la Familia localizada en el municipio de Santa Maria, Rio Grande do Sul. Los cuidadores familiares fueron indicados por el equipo de salud de la unidad. La recolección de datos ocurrió de julio a septiembre de 2010 y se desarrolló con entrevistas narrativas, orientadas por ejes norteadores. Del análisis de contenido temática surgieron categorías relacionadas a la comunicación y a las relaciones interpersonales entre profesionales, cuidadores familiares y enfermos, además de las interfaces entre los sectores de cuidado a la salud. Hay necesidad de una comunicación efectiva entre los sectores de cuidado, de modo que actúen conjuntamente, permitiendo cambio de saber que auxilien en el enfrentamiento del proceso de enfermedad.

Palabras clave: Enfermería. Enfermedad crônica. Atención Domiciliaria de Salud. Cuidadores. Comunicación.

\footnotetext{
${ }^{1}$ Enfermeira. Mestranda em Enfermagem do Programa de Pós-Graduação em Enfermagem (PPGEnf) da Universidade Federal de Santa Maria (UFSM). Membro do

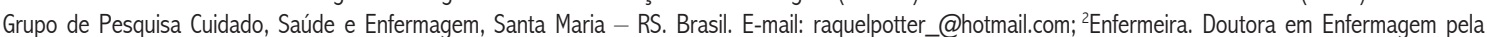
Universidade Federal de Santa Catarina (UFSC). Professora Associada do Departamento de Enfermagem e PPGEnf/UFSM. Orientadora do trabalho. Vice-Líder do Grupo de Pesquisa Cuidado, Saúde e Enfermagem, Santa Maria-RS. Brasil. E-mail: lourdesdenardin@gmail.com; ${ }^{3}$ Enfermeira. Mestre em Enfermagem pela UFSM. Doutoranda em Enfermagem pela Universidade Federal do Rio Grande do Sul (UFRGS). Co-orientadora do trabalho. Membro dos Grupos de Pesquisa: Núcleo de Estudos Interdisciplinares em Saúde (NEIS/UFSM); Cuidado Saúde e Enfermagem (UFSM) e Grupo de Estudos Culturais na Educação em Saúde e Enfermagem (UFRGS), Porto Alegre-RS. Brasil. E-mail:stefaniegriebeler@yahoo.com.br; ${ }^{4}$ Enfermeira. Doutora em Enfermagem pela Escola de Enfermagem Anna Nery da UFRJ. Professora Adjunta do Departamento de Enfermagem e do PPGEnf/UFSM. Membro do Grupo de Pesquisa Cuidado, Saúde e Enfermagem, Santa Maria-RS. Brasil. E-mail: margridbeuter@gmail.com; ${ }^{5}$ Enfermeira. Doutora em Enfermagem pela Escola de Enfermagem da USP. Professora Adjunta do Departamento de Enfermagem da UFSM. Membro do Grupo de Pesquisa Cuidado, Saúde e Enfermagem, Santa Maria-RS. Brasil. E-mail: nara.girardon@gmail.com
} 


\section{INTRODUÇÃO}

As doenças crônicas causam sérios efeitos na qualidade de vida dos indivíduos, além de provocarem mortes prematuras. A Organização Mundial de Saúde (OMS) estima que essas doenças poderão representar, no ano de 2015, 41 milhões do total de 64 milhões de óbitos mundiais ${ }^{1}$. No Brasil, devido a mudanças demográficas e epidemiológicas na população, os doentes crônicos procuram com mais frequência os serviços de saúde, apresentando agravos que podem causar alterações irreversíveis, graduais e, muitas vezes, demandar cuidados permanentes ${ }^{2}$.

Essas transformações exigem que os profissionais de saúde busquem novas maneiras de atender aos usuários, que não sejam somente pela visão biológica, mas também pela cultural, já que diversas ações são necessárias para tratamento e cuidados a longo prazo ${ }^{3}$. As famílias também necessitam de uma reorganização de sua dinâmica, buscando alternativas para melhor prover o cuidado aos doentes ${ }^{4} .0$ cuidado deve ser fundamentado em uma relação mútua de interação entre doente, família e serviços de saúde.

Para essa relação ser efetiva, a comunicação entre profissionais de saúde, paciente e família torna-se relevante, pois se caracteriza como um processo que pode servir como ajuda terapêutica, além de auxiliar na detecção de necessidades e promover a participação ativa dos sujeitos nas ações desenvolvidas ${ }^{5}$. Nessa interação, podem ser visualizados os setores de assistência à saúde, ou seja, o setor popular (familia e rede social), o setor folk (tradicional, compreendendo curandeiros, benzedeiros e outros) e o setor profissional (profissionais de saúde) $^{6}$.

Esses setores podem atuar um de cada vez ou conjuntamente, sobretudo, quando um deles não oferece 0 suporte necessário para a demanda do momento ${ }^{7}$. Ainda, existem as práticas integrativas e complementares que nem sempre são desenvolvidas por profissionais de saúde, mas que hoje se incorporam com legitimidade nas políticas de saúde do Sistema Único de Saúde (SUS), considerando metodologias participativas do saber popular e tradicional ${ }^{8}$. Apesar disso, um estudo revela que algumas formas de raciocínio diante das doenças são espećficas de cada um dos setores de assistência, o que pode dificultar a comunicação e aumentar a lacuna entre profissionais, paciente e família ${ }^{9}$.

Diante do exposto, faz-se necessário abordar a temática da comunicação e da relação entre os setores de cuidado, porque, além da lacuna existente nas pesquisas, esses fatores caracterizam-se como primordiais para a assistência aos doentes crônicos, os quais necessitam continuamente de cuidados e, consequentemente, da interação entre família, profissionais de saúde e doente. Além disso, a Enfermagem desenvolve cuidados próximos aos doentes, necessitando encontrar subsídios que a instrumentalizem na abordagem da família, já que diversos aspectos (culturais, psicológicos e sociais) do cotidiano desses indivíduos podem interferir no processo de doença. Diante das considerações apresentadas, 0 presente artigo busca descrever a inter-relação e a comunicação nos setores de cuidado à saúde, sob a perspectiva de cuidadores familiares de doentes crônicos com doença incapacitante.

\section{MÉTODOS}

Este artigo é parte integrante de uma pesquisa realizada com cuidadores familiares para a elaboraçã̃o de um Trabalho de Conclusão de Curso de Enfermagem, vinculado ao grupo de pesquisa Cuidado, Saúde e Enfermagem, da Universidade Federal de Santa Maria (UFSM). Trata-se de um estudo qualitativo, descritivo e exploratório que foi realizado no domicílio de usuários cadastrados em microáreas cobertas pela Estratégia de Saúde da Família (ESF), localizadas no Município de Santa Maria, Rio Grande do Sul.

Os sujeitos da pesquisa foram 11 cuidadores familiares de sete pacientes com Doenças Crônicas Não Transmissíveis (DCNT) incapacitantes. Algumas entrevistas foram realizadas em dupla (duas) ou trio (uma), quando outros familiares também se denominaram cuidadores, mesmo que o agendamento prévio tenha sido com apenas um deles. Os cuidadores familiares foram indicados pela equipe de saúde da ESF, caracterizando amostra proposital ${ }^{10}$. Foram incluídos na pesquisa cuidadores familiares de pacientes portadores de DCNT incapacitante, com idade superior a 18 anos e que realizavam a atividade por tempo igual ou superior a um ano. Os cuidadores identificados foram contatados por meio de visita ao domićlio dos pacientes. A primeira visita foi acompanhada pelo agente comunitário de saúde da microárea, a fim de facilitar a aproximação com os cuidadores.

Para a coleta de dados foram realizadas entrevistas narrativas, orientadas por eixos nor teadore ${ }^{11}$, visando obter informações relativas às interações entre profissionais de saúde, doente e família, na perspectiva dos cuidadores familiares. Empregou-se, ainda, um diário de campo para registro de observações, percepções, angústias, questionamentos e informações detectadas durante a realização da entrevista. A coleta de dados ocorreu no período de julho a setembro de 2010, sendo que o número de participantes da pesquisa foi definido pelo critério de saturação da amostra, ou seja, findou quando as informações iniciaram uma sequência de repetições ${ }^{10}$.

A execução do projeto iniciou após a aprovação institucional do município e do Comitê de Ética em Pesquisa da Universidade Federal de Santa Maria (UFSM), na data de 13 de maio de 2010, sob o Certificado de Apresentação para Apreciação Ética $n^{0}$ 0065.0.243.000-10, atendendo aos requisitos da Resolução 196/96 12 . 0 Termo de Consentimento Livre e Esclarecido foi entregue a cada participante no momento da entrevista e assinado em duas vias. Preservou-se o sigilo por meio da adoção de letras para a identificação dos participantes. 
As entrevistas foram gravadas, transcritas e analisadas conforme análise de conteúdo temática de $\mathrm{Minay}^{13}{ }^{13}$, a qual se constitui três etapas: pré-análise, exploração do material e tratamento dos resultados obtidos e interpretação. Na préanálise, as entrevistas foram lidas de maneira flutuante e, após, organizadas de forma a constituir o corpus do trabalho. Durante a etapa de exploração do material, buscou-se a codificação, e a transformação dos dados brutos em unidades semelhantes, que representaram, posteriormente, as categorias. Por fim, a fase de tratamento dos dados caracterizou-se pela busca de significados nas falas dos sujeitos, bem como interpretações e associações com o referencial teórico ${ }^{13}$.

\section{RESULTADOS E DISCUSSÃO}

\section{Os cuidadores familiares}

A pesquisa desenvolveu-se com 11 participantes, sendo três homens e oito mulheres. A faixa etária variou entre 19 e 70 anos, sendo que a maioria tinha idade superior a 50 anos. Com relação ao grau de parentesco, dois eram cônjuges, seis eram filhos, uma era sogra e duas eram netas. Três cuidavam há três anos (tempo mínimo de cuidado entre os entrevistados); dois cuidavam há quatro anos; dois, há sete; um, há oito anos; dois, há nove; e um, há 14 anos (tempo máximo de cuidado). Quanto aos doentes cuidados, havia seis mulheres e um homem. A faixa etária variou entre 61 e 91 anos, a maioria com idade superior a 76 anos. Quatro apresentavam sequelas de acidente vascular cerebral, dois com complicações circulatórias devido à diabetes mellitus e um com doença crônica pulmonar.

\section{Comunicação entre profissionais, cuidadores e pacientes}

Durante as entrevistas, perceberam-se vários relatos acerca da comunicação dos profissionais e dos serviços com os cuidadores e o doente. Segundo a percepção dos cuidadores, os serviços apresentavam lacunas quanto às orientações disponibilizadas, especialmente quando se iniciava a atividade de cuidador, na alta hospitalar.

\section{[...] na primeira vez, eles me largaram com a sonda, me deram o papel da dieta [...] e eu tive que correr atrás. [...] tu não sabe das coisas e não tem ninguém que te ensine (F).}

No início, que ela veio do hospital, [...] a gente não veio com recomendação nenhuma [...] dos cuidados que tinha que ter com ela (H).

As falas expressam que os familiares, ao assumirem 0 cuidado do doente no domicilio, ficam desamparados, carentes de informações e orientações para darem sequência ao tratamento.

Os cuidadores, em alguns momentos, sentem carência de informações sobre as práticas de cuidado necessárias para com o doente. Denotam o desejo de receber auxilio, o que poderia melhorar a qualidade de vida do familiar e também a sua, pois se reduziriam as sensações angustiantes, características da falta de conhecimento sobre determinada situação. Assim como as falas expressaram o descaso e a carência de orientações, características da falta de comunicação com os profissionais, a maioria dos entrevistados também demonstrou sua indignação com a precariedade de informações e transferência da responsabilidade dos cuidados para a família sem que ela esteja devidamente preparada.

0 cuidador familiar é quem deve receber dos profissionais de saúde as informações relevantes para o cuidado necessário para com o doente, pois ele será o responsável por essa prática ${ }^{14}$. Apesar disso, recebe pouca ou nenhuma orientação para assumir essa função; os saberes e as práticas são desenvolvidos na vida diária ${ }^{15}$.

Esses fatos apontam para questões relevantes dentro do espaço de cuidado domiciliar, fazendo emergir reflexões e questionamentos, tais como: Os cuidadores não estão recebendo orientações de cuidado dos profissionais? A maneira como essas orientações estão sendo prestadas é a mais adequada? Os profissionais de saúde atentam para os sentimentos emergidos do cuidador quando este assume a responsabilidade do cuidado de seu familiar?

Nesse sentido, surge uma possibilidade de reflexão a partir do contexto referido. A questão perpassa o caminho da comunicação, a qual é apresentada aos enfermeiros, no início da graduação, como um dos instrumentos básicos da Enfermagem. Ressalta-se que básico é considerado aquilo que é fundamental, essencial. Assim, é importante superar a fragilidade da comunicação entre profissionais e cuidadores/ doentes, pois, por vezes, os interesses de uns não correspondem às expectativas dos outros.

Vale ressaltar que o verbalismo não é absoluto como meio de comunicação; há de se considerar a comunicação não verbal, uma vez que os gestos e as expressões são inerentes às relações estabelecidas entre profissionais e cuidadores. Esse tipo de comunicação pode auxiliar no compartilhamento de informações sobre os cuidados, pois estar ao lado, segurar na mão e olhar nos olhos demonstram empatia e a possibilidade de uma maior aproximação entre os indivíduos, o que poderia contribuir para a união dos saberes entre os setores de cuidado e um melhor cuidado domiciliar.

A medicina moderna - muitas vezes limitada à doença, com ênfase em dados quantificáveis - pode não perceber as várias dimensões que permeiam os sentimentos e o estado emocional do doente e daqueles que o cercam 7 . Assim, um receptor desatento pode ter dificuldade em captar toda a mensagem que o emissor pretende transmitir, já que a comunicação está muito além de palavras, mas também envolve gestos, movimentos do corpo, expressões faciais e o toque ${ }^{16}$. Alguns doentes e familiares, no momento da alta hospitalar, podem estar ansiosos devido ao retorno ao domicílio, 
direcionando as atenções para esse espaço e fazendo com que ocorra uma diminuição na captação das orientações fornecidas.

Tal contexto remete aos questionamentos apresentados anteriormente. Talvez a justificativa para as falas seja de que a carência de informações é consequência da falta de preparo dos profissionais para desenvolver uma construção de saberes contínua e pertinente com os momentos vivenciados pelos cuidadores. Cabe, então, repensar criticamente as práticas de saúde, a fim de que se possa realmente integrar conhecimentos que permeiem a vida de um doente, reduzindo o tempo de adaptação dos saberes e das práticas dos cuidadores diante do cuidado dispensado para o paciente.

\section{Relações interpessoais entre profissionais, cuidadores familiares e pacientes}

Diversas relações podem ser estabelecidas entre profissionais de saúde, cuidadores e doentes. Em alguns momentos, essa relação pode ser bastante efetiva, como sugere a fala de grande parte dos cuidadores entrevistados, referindose, em especial, a médicos e enfermeiros:

Foi uma enfermeira que me trouxe um remédio caseiro (para alergia), [...] foi o que deu o xequemate (B).

O médico mandou eu dar uma metade à noite e uma metade de manhã (medicamento). Falei com o médico, ele deu [...] qual era o número (dosagem de oxigênio) ali para botar, me ensinaram também como usar o aparelho (tubo de oxigênio), tudo isso eu aprendi com os médicos (I).

Sob a visão dos cuidadores, percebe-se que as orientações de procedimentos e técnicas emergem de uma maneira considerável, tornando-se bastante representativas na relação entre profissional, doente e cuidador. A Medicina e a Enfermagem, como detentoras de um saber profissional, aparecem em diversos relatos, com orientações comuns às profissões ou específicas de cada uma. É nesse sentido que o saber profissional adentra os domicílios, permitindo que sejam incorporados e construídos conhecimentos por meio dessa interrelação entre os setores de cuidado.

Os profissionais de saúde fornecem orientações práticas, contribuindo para que o cuidador familiar adquira cada vez mais habilidade ${ }^{15}$ capazes de torná-lo autônomo no fazer das atividades de cuidado. No entanto, muitas vezes verifica-se que o sistema profissional ainda possui características de fragmentação, dificultando um auxílio qualificado ${ }^{9}$ e que preconize a integralidade do indivíduo.

Desse modo, faz-se necessário o desenvolvimento de atividades integrativas entre os núcleos de saber profissional e popular, facilitando a construção conjunta do conhecimento e também efetivando o processo relacional. Acredita-se que as ansiedades provenientes do cuidado domiciliar poderão ser reduzidas, uma vez que os doentes e a família passam a fazer parte do processo de aprendizado, sendo vislumbrados na sua totalidade.

Como um tipo de relação também presente nas falas dos entrevistados, ressalta-se aquela na qual os seus integrantes possuem maior afinidade, indo além do tecnicismo. Esse relacionamento destaca-se com a contribuição positiva do grupo de Fisioterapia da universidade, que presta assistência a grande parte das famílias entrevistadas.

\section{As meninas são muito carinhosas, atenciosas e conversam com ela [...], é uma "conversoterapia" (I).}

Apesar da característica profissional da fisioterapia e da utilização do seu saber para prestar orientações e realizar exercícios para os doentes, os cuidadores visualizam a sua prática como uma maneira de oferecer apoio social, o que afirma o caráter humanista preconizado atualmente para as profissões de saúde. Sendo assim, o vínculo e a escuta podem ser utilizados como estratégias de aproximação e estabelecimento de cuidados adequados ao contexto de cada um dos indivíduos. Ao contrário da Fisioterapia, a Enfermagem não foi relatada nas falas como praticante da conversa.

A intencionalidade de desenvolver relações de reciprocidade, de interação, de diálogo e de solidariedade caracteriza momentos de bem-estar e conforto. E, apesar de a conversa não ter sido destacada pelos cuidadores familiares entrevistados como prática de enfermagem, ela se caracteriza como parte integrante do cuidado de enfermagem, sendo ferramenta lúdica necessária para promover segurança e auxilio ao outro ${ }^{17}$.

A escuta e o desenvolvimento de práticas cuidadoras sensíveis promovem a comunicação e auxiliam na produção de um relacionamento de confiança entre profissionais e cuidadores, favorecendo o vínculo e o diálogo. Esses fatores podem colaborar para que as práticas se tornem coerentes com o contexto dos indivíduos, além de promoverem maior aceitação das atividades propostas. Contudo, a equipe de enfermagem referida por esse grupo parece se distanciar dessas tarefas, incorporando cada vez mais questões técnicas que pouco abrangem a inter-relação com o outro.

\section{Interfaces entre os setores de cuidado}

Essa categoria aborda os setores de cuidado à saúde e as inter-relações estabelecidas entre eles durante a trajetória do processo saúde/doença. Durante as entrevistas, a utilização de termos considerados científicos foi bastante presente nas falas dos cuidadores:

Acho que já tinha dado uma ameaça de isquemia nele [...] ele vinha vindo assim agarrado na parede [...] não conseguia se segurar (D). 
Não sei da onde que eu tirei, porque eu não tenho estudo, mas [...] a gente cuida [...] pra não criar $\operatorname{escara}(G)$.

Após o primeiro impacto acerca dos termos empregados pelos profissionais da saúde, os cuidadores, com o decorrer de suas vivências e experiências, passam a assimilar e a utilizar algumas nomenclaturas consideradas cientificas. Por vezes, estas são introduzidas no conhecimento popular, devido à associação de sinais e sintomas já visualizados no meio em que vivem, como quando a cuidadora $\mathrm{D}$ associa a isquemia à dificuldade de locomoção.

Percebe-se uma via de mão dupla, na qual termos médicos podem ser empregados tanto pelo setor popular quanto pelo profissional, pois, mesmo que teoricamente existam nomenclaturas específicas para determinadas organizações de cuidado, como os setores de saúde ${ }^{6}$, estes estão continuamente interligados, proporcionando mobilidade para as trocas de saberes e práticas de saúde em uma determinada sociedade. Acredita-se que, quando diversas pessoas de uma mesma comunidade têm harmonia quanto a um padrão de sinais e sintomas, sua significação e seu tratamento transformam-se em características de uma doença popular, já que esses fatores são influenciados pelo contexto sociocultural em que aparecem?

Porém, a dificuldade é que, nessa amplitude de terminologias, algumas podem ter significados diferentes para ambos os setores, ocasionando mal-entendidos e, consequentemente, falhas na comunicação ${ }^{7}$. Para haver comunicação efetiva, a ideia do emissor deve ter o mesmo significado para o receptor ${ }^{16}$. A construção do conhecimento deve ocorrer por meio de um processo horizontal e dialógico, no qual os profissionais atentem para a utilização de uma linguagem adequada, que considere elementos do contexto cultural e social de cada família4.

Salienta-se que, durante algumas entrevistas, detectouse certa insegurança dos cuidadores ao tentarem empregar termos originalmente cientificos ou ao explicar a sintomatologia da doença. Acredita-se que a apropriação dessas terminologias aos seus saberes pode estar sendo realizada de maneira errônea, causando constrangimento perante o pesquisador que, supostamente, detém o conhecimento por ser da área da saúde.

As áreas médicas podem impor, algumas vezes, certo status social, já que possuem o saber profissional ${ }^{7}$, o qual favorece uma posição de superioridade diante daqueles que não são da área da saúde. Nesta pesquisa, isso foi observado nas situações em que os cuidadores demonstraram desconforto na abordagem de assuntos referentes ao contexto profissional. Assim, verificase o distanciamento entre o setor popular e profissional, bem como a dificuldade para a produção e integração dos saberes, uma vez que os setores passam a desenvolver suas práticas paralelamente.

Essa barreira de conhecimento por vezes estabelecida entre os setores de assistência pode prejudicar o cuidado prestado ao doente, já que ambos têm relevância ao atender as necessidades advindas do cuidado domiciliar, devendo, portanto, desenvolver suas atividades de forma complementar. Conforme se observou, os sistemas de cuidado, na maioria das vezes, não são opositores, mas concordantes e complementares durante 0 itinerário de assistência ao enfermo ${ }^{3}$.

Inicialmente, apareceram falas nas entrevistas que indicam o seguimento de prescrições e regras estabelecidas pelo setor profissional:

Eu fui ali no postinho, falei com o doutor, foi como
eu adquiri isso aqui (sal para hipertenso). Tudo
que eu estou contando são autorizações dos
médicos pra fazer essas coisas (A).

A gente trata o sintoma, ela tá com uma dor de cabeça, dá um analgésico [...] o médico disse [...] Não fizemos automedicação de jeito nenhum (I).

Por meio dos registros do diário de campo, verificouse que o cuidador A demonstrou bastante ansiedade quando questionado sobre quem havia ensinado a ele o uso do sal para hipertensos. Logo referiu ser o médico, uma vez que acreditou que teria, provavelmente, um respaldo para justificar a compra do produto. A cuidadora I ainda demonstrou certa inquietação quando questionada sobre como tratava algumas intercorrências, como a dor. Tais situações remetem às próprias imposições realizadas, diversas vezes, pelos profissionais da saúde, os quais exigem, mesmo indiretamente, que as práticas de saúde dos indivíduos sejam desenvolvidas de acordo com as suas orientações.

0 poder atribuído aos profissionais, em virtude da sua formação profissional, proporciona aos doentes a adequação ao modelo médico de doença, ou seja, a incorporação das suas expressões na perspectiva dos pacientes ${ }^{7}$. Isso não quer dizer que, longe dos olhares médicos, as pessoas continuarão assumindo esse papel, pois fora desse contexto agem de acordo com seus aspectos culturais. Desse modo, pode-se afirmar que muitas situações vivenciadas e experienciadas ficam obscuras dentro do setor popular de cuidado.

Apesar de os profissionais de saúde estabelecerem hábitos e costumes necessários aos doentes, pôde-se constatar que, em vários momentos, os cuidadores entrevistados desenvolviam suas próprias maneiras de cuidar, as quais correspondiam a uma associação de saberes oriundos dos conhecimentos popular e científico:

Se ela tá com diarreia [...] a gente dáum chazinho (I).

Como ela tem diabetes, aquele dedo ficou dessa grossura. [...] Passava botando remédio, aquele 
iodado, sabe, e colocava naquilo ali, limpava e enchia de pomada, até que sarou (G.)

0 domicílio é o local onde as pessoas têm a possibilidade de exercer o seu saber. Não existem regras ou normativas; as atitudes pessoais construídas no decorrer da vida guiam as formas de agir. Quando os doentes parecem não necessitar de cuidados de urgência e emergência, o domićlio oferece as condições para uma tentativa de tratamento, mesmo que se visualizem características do saber profissional, como 0 medicamento relatado pelo cuidador $G$. 0 chá, devido ao seu contexto histórico, remete ao conhecimento popular, vinculado, sobretudo, aos aspectos culturais dos indivíduos, sendo utilizado em momentos que não são, aparentemente, característicos de uma emergência.

0 uso de recursos populares, como os chás, para assistência à saúde, pode representar uma maneira de respeito às crenças e aos valores do doente ${ }^{15}$. Esse fato revela a necessidade de os profissionais de enfermagem apresentarem maior domínio do saber popular, valorizando a cultura desses indivíduos, o que pode favorecer a proximidade das relações ${ }^{18}$. Ressalta-se que, desde 1978, a OMS tem expressado a necessidade de valorizar a utilização de plantas medicinais, uma vez que $80 \%$ da população é adepta do seu uso ${ }^{8}$.

Percebe-se que os saberes encontram-se interligados. Quando consideram necessário, os cuidadores recorrem aos outros sistemas de cuidado; em outros momentos, incorporam saberes e práticas desses sistemas no seu dia a dia; e, nas demais situações, buscam o desenvolvimento de atividades próprias do sistema popular. Essa associação de saberes e práticas está em constante modificação, dependendo dos sujeitos presentes em cada contexto social e da interação que eles estabelecem entre si. Em suma, o cuidado não pode ser classificado como algo imutável ou específico de um ou outro setor, e sim como fator resultante de uma interação entre questões socioculturais.

Nessa perspectiva, um dos cuidadores relatou buscar também auxílio em outros locais, que não especificamente associados ao setor profissional:

Tu sabe que a gente procura tudo que é recurso. Aí levei ela num centro de umbanda [...] Porque ela era uma pessoa normal, nunca teve problema (A).

A busca por maneiras de cuidado não ligadas ao setor profissional permeia a vida das pessoas, principalmente aquelas fortemente ligadas aos aspectos culturais de sua origem. Tais práticas não são orientadas pelos profissionais de saúde, mas encontram-se imbricadas no setor popular de cuidado, o qual opta pela estratégia que considerar mais adequada para 0 momento da doença.
As possibilidades de cura também podem ser compartilhadas no interior de seitas ou igrejas, já que no setor popular ou informal os integrantes podem ser fonte de aconselhamentos ou assistência para a saúde, sendo a confiabilidade transmitida de acordo com a experiência ${ }^{7}$. Assim, percebe-se que os setores de cuidado à saúde se interrelacionam por diversos momentos e que, após o doente retornar ao domicílio, a escolha de tratamento preconizada pela família somente poderá ser determinada pelos seus integrantes.

\section{CONSIDERAÇÕES FINAIS}

As maneiras de cuidar configuram-se nas mais variadas formas, o que reflete os aspectos culturais de cada família. Há necessidade dos profissionais de saúde, em especial, o enfermeiro, que apresenta maior contato com os cuidadores e doentes, atentarem para práticas que contextualizem os saberes e vivências populares. Com isso, torna-se possível uma aproximação dos setores de cuidado, o que pode auxiliar na produção de vínculos, estabelecer relações de confiança que favoreçam a troca de saberes e ainda evitar que o cuidado no domićílio seja solitário e angustiante para os cuidadores.

Salienta-se que as dificuldades e as carências enfrentadas pelos cuidadores, essencialmente durante 0 impacto inicial de assumirem tal responsabilidade, caracterizam momentos estressantes, cabendo ao profissional que está próximo ter a sensibilidade de prestar apoio afetivo, não somente informações acerca da doença e dos cuidados, que provavelmente não serão lembrados por esse cuidador no futuro. Considera-se a relevância de construir um conhecimento mútuo, que esteja de acordo com as possibilidades de cada cuidador, paciente, bem como do domicílio. Dessa forma, a comunicação, seja ela verbal ou não, como instrumento básico de Enfermagem, deve estar ancorada como pano de fundo nas atividades preconizadas com os cuidadores, o que auxilia na melhor interação entre esses dois setores de cuidado. Eles devem caminhar juntos e de maneira complementar, delineando abordagens que vislumbrem situações promotoras de saúde e qualidade de vida para o doente crônico dependente.

Cabe destacar, ainda, que o setor de assistência à saúde folk não foi contemplado neste estudo, o que pode ter ocorrido devido à utilização do eixo norteador escolhido, ou pelas entrevistas narrativas como método de coleta de dados. Essa ampla temática não se finda aqui, abrindo lacunas para futuros trabalhos que possam complementar as ideias expostas e ainda trazer considerações relevantes para o cuidado domiciliar em saúde. 


\section{REFERÊNCIAS}

1. Organização Mundial da Saúde- OMS. Preventing chronic diseases a vital investments. [on-line]. 2005; [citado 2010 out 20]; 202 p. Disponível em: http://whqlibdoc.who.int.

2. Ministério da Saúde (BR) . Diretrizes e recomendações para o cuidado integral de doenças crônicas não-transmissíveis: promoção da saúde, vigilância, prevenção e assistência. Textos básicos de atenção à saúde. Série pactos pela saúde. [on-line] 2008; [citado 2010 jul 24].Disponível em: http://portal.saude.gov.br .

3. Boehs AE, Monticelli M, Wosny AM, Heidemann IBS, Grisotti M. A interface necessária entre enfermagem, educação em saúde e o conceito de cultura. Texto\& Contexto Enferm. 2007 abr/jun; 16(2): 307-14.

4. Brondani CM, Beuter M. A vivência do cuidado no contexto da internação domiciliar. Rev Gauch Enferm. 2009; 30(2): 206-13.

5. Pontes AC, Leitão IMTA, Ramos IC. Comunicação terapêutica em enfermagem: instrumento essencial do cuidado. Rev Bras Enferm. 2008 maio/jun; 61(3): 312-18.

6. Kleinman A. Orientations 2: culture, health care systems and clinical reality. In: Kleinman, A. Patients and healers in the context of culture. London: University of California Press; 1980. p.24-70.

7. Helman C. Cultura, saúde e doença. $4^{\mathrm{a}}$ ed. Por to Alegre: Artmed; 2003.

8.Ministério da Saúde (BR). Secretaria de Atenção à Saúde. Departamento de Atenção Básica. Política Nacional de Práticas Integrativas e Complementares no SUS - PNPIC-SUS. [on-line]. Brasilia(DF); 2006; [citado 2011 set 29]; Disponível em: http://bvsms.saude.gov.br

9. Visentin A, Lenardt MH. 0 itinerário terapêutico: história oral de idosos com câncer. Acta Paul. Enferm. 2010; 23(4): 486-92.

10. Turato ER. Tratado da metodologia da pesquisa clínico-qualitativa: construção teórico-epistemológica, discussão comparada e aplicação nas áreas da saúde e humanas. Petrópolis(RJ): Vozes; 2008.

11. Silva DGV, Trentini M. Narrativas como técnica de pesquisa em enfermagem. Rev Latino-Am Enfermagem. [periódico on-line]. 2002 maio/ jun; [citado 2011 mar 02]; 10(3): 423-32. Disponível em: http:// www.scielo.br .

12. Ministério da Saúde (BR). Conselho Nacional de Saúde. Resolução n 196, de 10 de outubro de 1996. Diretrizes e normas regulamentadoras de pesquisas envolvendo seres humanos. Brasília (DF); 1996.

13. Minayo MCS, organizador. Pesquisa social: teoria, método e criatividade. $26^{a}$ ed. Petrópolis(RJ): Vozes; 2007.

14. Girardon-Perlini NMO, Faro ACM. Cuidar da pessoa incapacitada por acidente vascular cerebral no domicílio: o fazer do cuidador familiar. Rev Esc Enferm USP. [periódico on-line]. 2005; [citado 2011 mar 10]; 39(2): 154-63. Disponível em: http://www.scielo.br .
15. Pedro KS, Marcon SS. Perfil e vivência dos cuidadores informais de doentes crônicos assistidos pelo NEPAAF-Núcleo de estudos, pesquisa, assistência e apoio à família. Online Braz J. [periódico on-line]. 2007; [citado 2011 jan 26]; 6(1): [aprox. 8 telas]. Disponível em: http:// www.objnursing.uff.br.

16. Júnior AB, Matheus MCC. Comunicação. In: Cianciarullo TI, organizador. Instrumentos básicos para o cuidar: um desafio para a qualidade de assistência. São Paulo: Atheneu; 1996. p.61-73.

17. Beuter M, Alvim NAT. Expressões lúdicas no cuidado hospitalar sob a ótica de enfermeiras. Esc Anna Nery. 2010 set; 14(3): 567-74.

18. Badke MR, Budó MLD, Silva FM, Ressel LB. Plantas medicinais: o saber sustentado na prática do cotidiano popular. Esc Anna Nery. 2011 jan/ mar; 15(1): 132-39. 